\title{
EDITORIAL
}

\section{Dust and Sand Storms (DSS) in East Asia}

\author{
Youngsin Chun ${ }^{1}$, Yaping Shao ${ }^{2}$, and Masataka Nishikawa ${ }^{3}$ \\ ${ }^{1}$ Asian Dust Research Division, National Institute of Meteorological Research, Korea Meteorological Administration, Korea \\ ${ }^{2}$ Institute of Geophysics and Meteorology, University of Cologne, Germany \\ ${ }^{3}$ National Institute for Environmental Studies, Japan
}

(C) The Korean Meteorological Society and Springer 2013

Predicting Dust and Sand Storms (hereafter DSS) that are accompanied by strong winds and suspended aerosol particles, and understanding the mechanism involved, present significant challenges. These events exert a considerable effect on the ecosystem, by degrading the air quality and by modifying the radiation balance in Northeast Asia. DSS originates in the dry and semi-arid areas in southern Mongolia and northern China (Shao and Dong, 2006), as the result of strong winds associated with low-pressure systems (Fig. 1). Unlike DSS in Mongolia and China, the dustfall or the floating dust appears in downwind regions such as the Korean Peninsula and the Pacific Ocean. The historical term "Woo-Tou (雨土)," which means "dust-fall" in Korean, is the name of the substance descending from the atmosphere, which is unrelated with water droplets. This term is evident in historical records, exemplified by the documentary entry traced back to 174 A.D, during the reign of King Adalla of the Silla Dynasty (Chun et al., 2008).

DSS occurrences often have an adverse impact on organisms' life styles and their environment, not only in the source region but also in the downwind regions. Suspended particles can cause low visibility, respiratory diseases, and damage to the precision industry. A strong international cooperation in East Asia is necessary in order to solve this transcendent, widespread problem. Data exchange is in high demand, both for figuring out characteristics of dust phenomena and for forecasting them properly. For example, $\mathrm{PM}_{10}$ concentrations in the source region, along the pathway of dust deposition, are essential to forecasting dust events quantitatively. Given these points, a regional network for DSS, formed by Northeast Asian countries, such as Mongolia, China, Korea and Japan, would provide concrete opportunities for scientific cooperation against DSS.

The Tripartite Environment Ministers Meeting among China, Japan and Korea (TEMM) established Joint Research on DSS, among these nations, and policy for international cooperation. In Joint Research on DSS, two Working Groups have been formed-one to monitor and forecast DSS (WG I), and the other to prevent DSS by planting trees in arid areas (WG II). The first meeting of WG I was held in Seoul, Korea in 2008 to

Corresponding Author: Youngsin Chun, Asian Dust Research Division, National Institute of Meteorological Research, Korea Meteorological Administration, Seoul 156-720, Korea.

E-mail: hwangsa@korea.kr achieve these shared goals and was followed by joint workshops and meetings in Shenyang, China in 2009 (an ad-hoc meeting organized by Korea); Tokyo, Japan in 2009; Seogwipo, Korea in 2010; Neimenggu, China in 2011(a joint meeting with WG II); Beijing, China in 2011; and Fukuoka, Japan in 2012. Mongolia has been joining these meetings since the 2009 meeting in Shenyang. WG I has been successfully conducting joint research for the selected dust cases by sharing observational data and forecasting skills of each participant country (Table 1).

In the first phase, WG I focused on DSS that occurred in 2007. The research findings were published in Japan in 2011 in the special issue of Scientific Online Letters on the Atmosphere (SOLA), which includes various scales of dust research products, such as meteorological features from dust occurrence to transport, data assimilation using Lidar, dust model intercomparison study, and the effects of the source region condition on model simulation (e.g., Chun and Kim, 2011; Nishikawa et al., 2011).

This special issue was stimulated by the collective efforts from WG I activities for the years of 2010 and 2011, and the volume contains research papers on meteorology-related dust occurrence and transport, in-situ measurement and remote sensing, numerical simulation and validation of dust models, soil characteristics of the source region, and estimation of dust emission by inverse model analysis.

In this special issue, $K u$ and Park attempted to reduce uncertainties with dust emissions, by using an inverse modeling technique and obtained optimized dust emissions. Kang et al. investigated the effect of frozen soil on dust emission through a case study of a severe wintertime East Asian dust event, using WRF/Chem with a new dust emission scheme. Park et al. estimated the dust emission in the Asian dust source region and both dry and wet depositions for dust events, which are observed in Korea during the period of 20 to 29 December 2009. Similarly, Mao et al. investigated the influence of vegetation variations on dust activity over Northeast Asia during springtime. Shin et al. reported optical properties of Asian dust particles from lidar measurements, and Sugimoto et al. analyzed dust events in 2008 and in 2009, with the lidar network observations and surface observations in China, Korea, Japan, and Mongolia. Sohn et al. explained the reason behind weakening or disappearing brightness temperature difference 


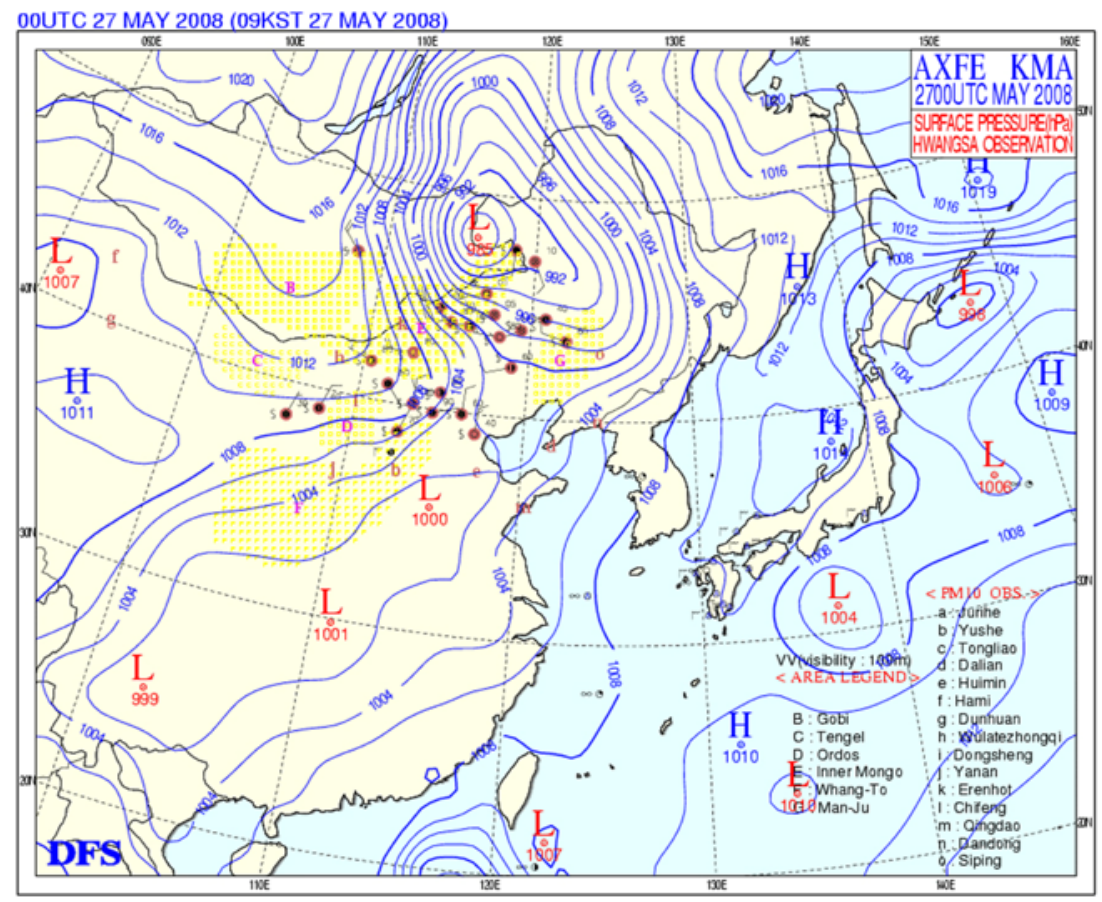

Fig. 1. Dust weather chart provided by KMA for 0000 UTC on 27 May 2008. The chart displays surface pressure patterns (blue lines) and dust phenomena (red circles) over the Northeast Asian domain. It shows dust records over eastern Mongolia and Inner-Mongolia, which are induced by strong wind associated with an intense low pressure system.

Table 1. Items and periods of shared data in each country for this special issue.

\begin{tabular}{|c|c|c|}
\hline Country & Items (number of sites) & Period of data \\
\hline Mongolia & Hourly average $\mathrm{PM}_{10} \& \mathrm{PM}_{2.5}(2$ sites), visibility ( 2 sites by visibility meter $)$ & 24 May to 4 June 2008 \\
\hline China & Daily average $\mathrm{PM}_{10}(10$ sites $)$ & 12 25 March 2009 \\
\hline Korea & Hourly average $\mathrm{PM}_{10}$ ( 36 sites), LIDAR ( 2 sites), visibility ( 6 sites by visibility meter) & 13 26 October 2009 \\
\hline Japan & $\begin{array}{l}\text { Hourly average of SPM (21 sites), } \mathrm{PM}_{10}(11 \text { sites }), \mathrm{PM}_{2.5}(2 \text { sites }) \text {, } \\
\text { LIDAR (11 sites), } 3 \text { hourly visibility ( } 76 \sim 85 \text { sites) }\end{array}$ & 15 28 December 2009 \\
\hline
\end{tabular}

(BTD) signatures, in particular, over the Yellow Sea on March 15-16, 2009. H. Lee et al. investigated meteorological, physical, and chemical characteristics of two severe dust events in spring and winter, and Wang et al. explored the influence of DSS on urban air quality in China during 2005-2010, together with the analysis of a severe DSS event from 26 to 31 in May 2008. Fan et al. demonstrated the impact of a strong dust storm episode on the particle matter in Guangzhou in April 2009, including various particle chemical components. E.-H. Lee et al. presented results from the experiments of surface $\mathrm{PM}_{10}$ assimilation for the operational forecasting of dust concentration, with a data assimilation method, and also evaluated the performance of the operational dust model in Mongolia during the period of three months from March to May 2011.

We hope that the research activities, documented in this special issue, would assist in enhancing our understanding on how to better monitor and forecast Asian dust.

Acknowledgement. We, the guest editors of this special issue of Asian Dust and Sand Storms, acknowledge that this issue is a part of the contribution to international Joint Research on DSS under TEMM. We are grateful to all the authors, reviewers, and TEMM staff, and the APJAS editorial board. This research was conducted as part of "Development and application of technology for weather forecasting (NIMR2012-B-1)" in NIMR, Korea.

\section{REFERENCES}

Chun, Y., H. K. Cho, H. S. Chung, and M. Lee, 2008: Historical records of Asian dust events (Hwangsa) in Korea. Bull. Amer. Meteor. Soc., DOI: 10.1175/2008 BAMS2159.1.

, and S. Kim, 2011: Meteorological Features and Particulate Matter Monitoring of the Asian Dust (Hwangsa) Event Observed in Korea on 1 April 2007, Sci. Online Lett. Atmos., 7A, 017-020.

Nishikawa, M., I. Mori, K. Takahashi, I. Matsui, N. Sugimoto, K. Kawamoto, Y. Wang, and S. Dong, 2011: Short-Term Variations in Aerosol Components during the Same Asian Dust (Kosa) Event Observed in Nagasaki, Japan and Beijing, China, Sci. Online Lett. Atmos., 7A, 009-012.

Shao, Y., and C. H. Dong, 2006: A review on East Asian dust storm climate, modeling and monitoring, Global Planet. Change, 52, 1-22. 